\title{
Dusky dolphin and tourist interaction: effect on diurnal feeding behavior
}

\author{
Silvana L. Dans*, Enrique A. Crespo, Susana N. Pedraza, Mariana Degrati, \\ Griselda V. Garaffo
}

Laboratorio de Mamíferos Marinos, Centro Nacional Patagónico, Blvd. Brown 3600, (9120) Puerto Madryn, Chubut, Argentina

Facultad de Ciencias Naturales, Universidad Nacional de la Patagonia, Blvd. Brown 3700, (9120) Puerto Madryn, Chubut Argentina

\begin{abstract}
Dolphin watching is a relatively newly developed tourist activity. Although it is assumed to contribute to the conservation of marine ecosystems, its long-term adverse effects are still unknown. The present work aims to assess the impact of tour vessels on the behavior pattern of dusky dolphins displaying diurnal and cooperative feeding. We evaluated potential bias of commercial vessels to specific activities, short-term responses of dolphins to vessel approach, and longer-term effects of these changes, particularly on the activity budget and the time dolphins need to resume an activity. Several field experiments were carried out in which dolphins were approached by a research vessel or by commercial vessels. Group tracking was also made from a research vessel. Behavioral sequences were modeled by stochastic matrix models. Activity budget and time to return to an activity were obtained from matrix properties. Commercial trips found mostly feeding groups. Feeding showed the highest rate of change at the moment of vessel approach, and commercial vessels had an effect on the direction of change. Over the longer term, feeding and socializing time budgets decreased when commercial vessels were present. The time to return to feeding as well as the time it took for a group of dolphins to feed increased in the presence of commercial vessels. Dusky dolphins in South Atlantic waters feed during the day on patchily distributed prey. Our study demonstrates that boat presence negatively affects the longer-term feeding efficiency of dusky dolphins.
\end{abstract}

KEY WORDS: Markov chains - Activity budget $\cdot$ Behavior sequences $\cdot$ Dusky dolphins $\cdot$ Human disturbance $\cdot$ Pelagic feeding

Resale or republication not permitted without written consent of the publisher

\section{INTRODUCTION}

Whale and dolphin watching is a relatively new activity developed within the concept of ecotourism. The activity is growing fast and expanding worldwide, providing huge incomes for many countries (Hoyt 2001). The activity is also encouraged in a conservation context, assuming it could enhance respect for marine wildlife and probably replace other consumptive uses that have clear negative effects on populations and marine ecosystems. However, some concerns exist about potential long-term effects on whales and dolphin populations, as well as on marine systems in general.

The assessment of the impact of recreational and tourist activities may also have important practical consequences in a management framework. (Taylor \& Knight 2003, Borkowski et al. 2006). If disturbance has severe effects, human presence will need to be minimized to avoid population declines or habitat shifts. However, a thorough evaluation of impacts is often not possible due to limited understanding of the ecological processes of a particular marine system. Identification of the major factors related to the distribution and 
behavior of a species is needed before the role of disturbance in altering these relationships can be examined (Gill et al. 2001).

In dolphin watching, tours involve searching for dolphins and approaching them from vessels, and in some locations, swimming with and also feeding them. Several behavioral responses have been reported, such as longer inter-breath intervals, avoidance, and changes in swimming speed in bottlenose dolphins Tursiops truncatus and killer whales Orcinus orca (Nowacek et al. 2001, Williams et al. 2002, Constantine et al. 2004). Some studies also revealed longterm effects, e.g. a distribution shift in Indo Pacific bottlenose dolphins (Tursiops sp.) in Shark Bay, Western Australia, as a consequence of long-term exposure to disturbance (Lusseau 2005, Bedjer et al. 2006). It is not yet clear how these behavioral responses are related to survival or reproduction, and ultimately to population sustainability. Changes in female reproductive success were detected in only a few cases in which individuals were identified and monitored for a long period (Mann et al. 2000).

A novel approach in evaluating the effect of tour boats on dolphins involves translating behavioral changes to energetic costs through measurement of time budgets for different activities (Lusseau 2003, Williams et al. 2006, Stockin et al. 2008). Few studies have demonstrated a decrease in foraging time budget, with consequent decrease in energy acquisition. The biological consequences of this response probably depend on the foraging strategy of the species.

Dusky dolphins Lagenorhynchus obscurus are mesopelagic feeders that inhabit waters on the continental shelf of South America, South Africa and New Zealand. They are an important attraction for tourism in several locations, but the impact of tourism on this species is less known than for other dolphin species. Detailed shore-based studies of both short-term (Barr \& Slooten 1999) and long-term responses of dusky dolphins to boats and swimmers in New Zealand indicate that the effects of tours are minimal (Markowitz 2004). In Argentina, however, dusky dolphins showed a short-term reaction to boats, and feeding was the most affected behavior. Almost half of the time when dolphins were disturbed during feeding, they changed their behavior (Coscarella et al. 2003). The normal transition from one activity to another could be severely affected if the source of disturbance is sustained and repeated.

In Argentina, dusky dolphins exhibit an activity pattern that is different from that exhibited in New Zealand, suggesting differences in foraging strategy. In Kaikoura, New Zealand, dolphins feed at night and mainly travel, rest and socialize in very large groups of up to 1000 ind. during daylight hours (Cipriano 1992,
Würsig et al. 1997). In Argentina, dolphins contrastingly feed during daylight hours in smaller groups, on pelagic schooling fishes by means of a particular cooperative strategy (Würsig \& Würsig 1980). Recently, it has been proposed that some traveling bouts could have a foraging function (Degrati et al. 2008). These results suggest that feeding efficiency may be seriously affected by disturbance of behavioral sequences. Thus, behavioral responses to boats and tourists, which operate during the day, may have biologically different consequences.

The dusky dolphin population off the Argentinian coast is also affected by incidental takes in trawls (Dans et al. 2003). Annual mortalities are close to sustainable levels (Dans et al. 2003) and the population may not be able to sustain additional stressors. The present work therefore aims to assess the effect of tourist boats on the behavioral pattern of dusky dolphins. We first evaluated potential bias of commercial vessels to specific activities, and then evaluated longer-term effects of changes in behavior sequences, particularly on the activity budget and the time dolphins need to resume an activity.

\section{MATERIALS AND METHODS}

Study area and observation platforms. We studied dusky dolphins inhabiting Golfo Nuevo on Península Valdés, a protected area in Argentina that was declared a World Heritage Site by UNESCO in 1999 $\left(42^{\circ} 20^{\prime}\right.$ to $42^{\circ} 50^{\prime} \mathrm{S}, 64^{\circ} 20^{\prime}$ to $\left.65^{\circ} 00^{\prime} \mathrm{W}\right)$ (Fig. 1). This

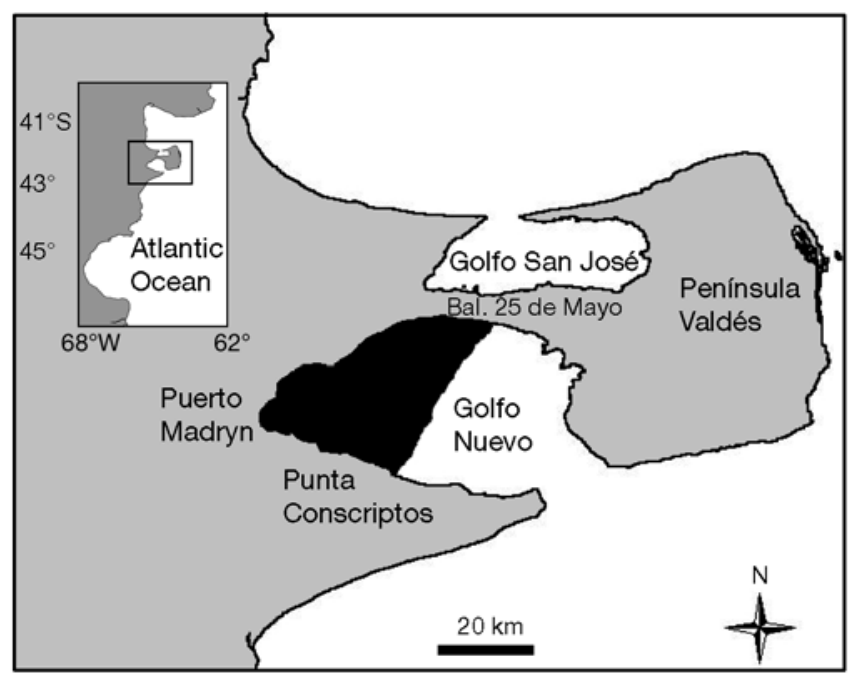

Fig. 1. Península Valdés showing Golfo Nuevo and the study area. Research and commercial vessels operated from Puerto Madryn harbor. Black area is where commercial vessels usually looked for dolphins and where experiments were carried out 
gulf is a semi-enclosed $2500 \mathrm{~km}^{2}$ basin that is $70 \mathrm{~km}$ long and $60 \mathrm{~km}$ wide, with a maximum depth of $184 \mathrm{~m}$, and is connected to the Atlantic Ocean through a shallow sill of $16 \mathrm{~km}$ width (Mouzo et al. 1978). The gulf represents a small portion of the distribution range of the species in the southwestern South Atlantic, although the depth range within it is similar to the continental shelf outside, and group sizes are similar to those sighted in open waters (Crespo et al. 1997, Coscarella et al. 2003). There is no information about the population size within the bay, nor its connectivity with other areas, but there is some evidence that dolphins move outside and over long distances (Würsig \& Bastida 1986). Several identified animals have been sighted in different years, as well as in Golfo San José (G. V. Garaffo unpubl. data) (Fig. 1).

Ship-based surveys were carried out between January and April, from 2001 to 2005. Land-based observation was discarded due to the distance from the coastline to where dolphins occur (4 to $8 \mathrm{~km}$ ) (Garaffo et al. 2007) where commercial vessels operate. Tourism vessels operated from Puerto Madryn, and usually looked for dolphins as far as Baliza 25 de Mayo in the north and Punta Conscriptos in the south (Fig. 1).

Both commercial and research vessels were used as observation platforms to carry out several experiments. Two research vessels were used: a $6 \mathrm{~m}$ fiberglass boat with a 50 HP outboard engine from 2001 to 2003, and a $7 \mathrm{~m}$ fiberglass boat with a $105 \mathrm{HP}$ outboard engine from 2004 to 2005. Three different commercial vessels operated: one $11 \mathrm{~m}$ fiberglass boat, and 2 inflatable boats of 8 and $10 \mathrm{~m}$ length, all with outboard engines. Boats did not operate simultaneously during the whole study period, but a maximum of 2 commercial vessels operated at the same time with the same group of dolphins.

Expt 1, dolphin activity and response to boat approach. This experiment allowed detection of possi- ble bias towards specific groups or behaviors as well as the immediate response of dolphins to different ways of approaching them. Both research and commercial vessels were used as observation platforms. Researchers boarded monitored commercial trips. Commercial operators were allowed to behave normally in the searching tactic as well as during the approach. Research surveys consisted of random transects throughout the study area, until a group of dolphins was detected. Both kinds of surveys were done by the same researchers under similar temporal and spatial conditions.

Observations were done at the group level since dusky dolphins in Golfo Nuevo occur in groups of 10 to 100 ind. (Degrati et al. 2008), and groups are distinctive enough in the field. The behavioral state was assigned by scan sampling (Altman 1974) before the boat approached the group, i.e. at a distance of $\sim 200 \mathrm{~m}$ estimated visually. For this purpose, researchers were previously trained by allowing them to estimate distances to other objects, flocks of birds or other small recreational boats, and then corroborating estimated distances with those measured by a GPS. The predominant activity was determined as the state in which most of the individuals were engaged. Five activity categories were defined (Table 1). Data were arranged in contingency tables, classifying each group by the activity at $200 \mathrm{~m}$, and by boat type (commercial or research). Differences in the activity in which groups were found were analyzed using $\chi^{2}$ test.

Once the activity was assigned at $200 \mathrm{~m}$, the group was approached closer. Different distances and ways of approaching were performed. The research boat approached dolphins from the side in the same direction and speed and at a minimum distance of $100 \mathrm{~m}$, while the commercial boat approached dolphins from any direction and at a distance of $50 \mathrm{~m}$ or less. The predominant activity was reassigned once the boat was

Table 1. Lagenorhynchus obscurus. List of behavioral states or activities of groups used in this study

\begin{tabular}{|c|c|}
\hline Activity & Description \\
\hline Feeding $(\mathrm{F})$ & $\begin{array}{l}\text { Animals move fast, diving and emerging in all directions. Sometimes it is possible to see dolphins harassing } \\
\text { fish, fish jumping out of water, and marine birds like terns, gulls, albatrosses, giant petrels, shearwaters, cor- } \\
\text { morants, jaegers, and others, feeding at the same time. Animals move fast but the group does not change } \\
\text { location. }\end{array}$ \\
\hline Traveling $(\mathrm{T})$ & Animals move continuously in a predominant direction with few or no interruptions. \\
\hline Socializing $(\mathrm{S})$ & $\begin{array}{l}\text { Animals are in almost constant physical contact with each other. Belly to belly swimming and copulations } \\
\text { appear to take place during this activity, as well as display of aerial behaviors (noisy and clean leaps, spy } \\
\text { hopping). }\end{array}$ \\
\hline Resting (R) & $\begin{array}{l}\text { Animals tightly grouped, swimming slowly with numerous direction changes, almost without forward } \\
\text { propulsion. }\end{array}$ \\
\hline Milling (M) & Animals move slowly and change direction continuously. \\
\hline
\end{tabular}


closer to the dolphins. Data were arranged in two $5 \times 5$ contingency tables (one for each boat), considering the activity at $200 \mathrm{~m}$ and the activity once the boat approached closer. Direction of change was evaluated using the McNemar test (Zar 1996).

Expt 2, effect of boat interaction on activity pattern. This experiment allowed evaluation of longer-term effects of behavioral changes on activity budget. Other aspects of the activity pattern were also evaluated, for example the mean time to return to an activity, and the mean time to pass from one activity to another. These 2 parameters may indicate the probability of dolphins resuming an activity once their behavior has been altered.

For this experiment, only the research vessel was used as the observation platform. Once a group was detected and approached at $\sim 100 \mathrm{~m}$, it was followed for at least $30 \mathrm{~min}$ but for as long as possible. Commercial vessels could visit the focal group at the same time. Since the research vessel approached the dolphins from the side in the same direction and at constant speed, and behavior and distance to the dolphins remained relatively constant while following them, the potential effect on dolphin behavior was minimized and remained constant. This procedure allowed us to control the effect of the research vessel for the approximation of commercial vessel effects (Lusseau 2003). During the focal-group tracking, the predominant activity was recorded every $2 \mathrm{~min}$ (Lehner 1998), along with the presence and number of commercial vessels. The survey was ended if sea state deteriorated (usually at Beaufort 4 or more) since following dolphins and assessing their activity became imprecise. In 2002, the research vessel was not available.

Since behavior at consecutive 2 min intervals was not independent, we modeled sequences by Markov chains (Bakeman \& Gottman 1997). Markov chains quantify the dependence of an event on preceding events. Transition probabilities - i.e. the probability of a specific activity occurring, given the occurrence of another activity - can conform with a stochastic matrix model. These models generate a set of useful properties (Grinstead \& Snell 1997), and are commonly applied to population dynamics and more recently to community succession and behavior (Caswell 2001, Lusseau 2003, Hill et al. 2004).

Each 2 min interval was classified according to the activity at the previous interval (preceding activity), the activity at the interval (succeeding activity), and the presence or absence of commercial boats (control: only research vessel present; impact: research and commercial vessels present at the same time). When an impact chain followed a control chain or vice versa, the transition between them was discarded.
Transition probabilities were calculated as:

$$
p_{i j}=\frac{a_{i j}}{\sum_{j=1}^{5} a_{i j}}
$$

where $p_{i j}$ is defined as the transition probability from activity $i$ to activity $j, a_{i j}$ is the number of 2-min intervals in which activity $i$ was followed by activity $j$,

and

$$
\sum_{j=1}^{5} p_{i j}=1
$$

Control and impact transition probabilities were obtained separately from control and impact chains, and compared by pairs using the binomial test (Zar 1996).

Transition probabilities were arranged in a 'control' and 'impact' row-stochastic matrix. Each matrix contained 5 rows (preceding activity i) and 5 columns (succeeding activity $j$ ), where each cell represented the transition probability from one activity to another, and all probabilities in a row summed up to 1. From ergodic properties of Markov chains, the probability of observing a specific activity at a specific time was calculated from the left eigenvector $\boldsymbol{w}$ of the matrix. This row vector represented the stationary distribution of a Markov chain, and its components $w_{i}$ summed up to 1. In our analysis, $\boldsymbol{w}$ represents the activity budget of dolphins and each $w_{i}$ represents the proportion of time spent in activity $i$.

The assumption of stability in transition probabilities was tested. 'Control' intervals were classified by year (2001, 2003 and 2004), and frequencies were arranged in a $5 \times 5 \times 3$ contingency table (preceding vs. succeeding activity vs. year). The effect of time on transitions was analyzed using log-linear models, comparing the fully saturated model to the model with all the 2-way interactions, using $\Delta G^{2}$ statistics.

The left eigenvector was obtained with Poptools 2.4 (CSIRO), for control and impact matrices. Differences between budgets were tested using Z-test of proportions (Zar 1996).

The mean recurrence time $r_{i}$, defined as the time to return to activity $i$, was calculated as:

$$
r_{i}=\frac{1}{w_{i}}
$$

where $w_{i}$ is the $i$ th component of $\boldsymbol{w}$. This quantity represents the expected time to return to an activity once it was interrupted.

The mean first passage time $m_{i j}$, defined as the time to go from one activity $i$ to another activity $j$, was calculated as:

$$
m_{i j}=\frac{z_{j j}-z_{i j}}{w_{j}}
$$


where $z_{i j}$ and $z_{i j}$ are components of the fundamental matrix $\mathbf{Z}, w_{j}$ is the $j$ th component of $\boldsymbol{w}$, and $i \neq j$. The fundamental matrix $\mathbf{Z}$ is the inverse of the matrix $\mathbf{I}-\mathbf{P}+$ $\mathbf{W}$, where $\mathbf{I}$ is the identity matrix, $\mathbf{P}$ is the probability matrix, and $\mathbf{W}$ is the matrix all of whose columns are the vector $\boldsymbol{w}$ (Grinstead \& Snell 1997). This quantity represents the expected time to reach an activity for the first time, and can be called the 'waiting' time.

\section{RESULTS}

\section{Groups, behaviors and reaction to boat approach}

A total of 156 groups of dolphins were found and approached, 93 by commercial vessels and 63 by the research vessel. The activity before the approach was different depending on the vessel $\left(\chi^{2}=17.971, \mathrm{df}=4\right.$, $p=0.00125)$. Commercial vessels mainly found feeding groups (43\%) and no resting groups (Fig. 2). On the other hand, the research boat found the same proportion of feeding and traveling groups (39 and $38 \%$ ), and also found resting groups (Fig. 2). The activity of dolphins once the vessel approached them also depended on the vessel, with the commercial vessel increasing traveling by a larger proportion $\left(\chi^{2}=14.168, \mathrm{df}=4, \mathrm{p}=\right.$ 0.00678) (Fig. 2).

Responses of dolphins to vessel approach also depended on the activity when approached. Feeding and milling groups changed their activity for half of the commercial boat approaches, while traveling, socializ-

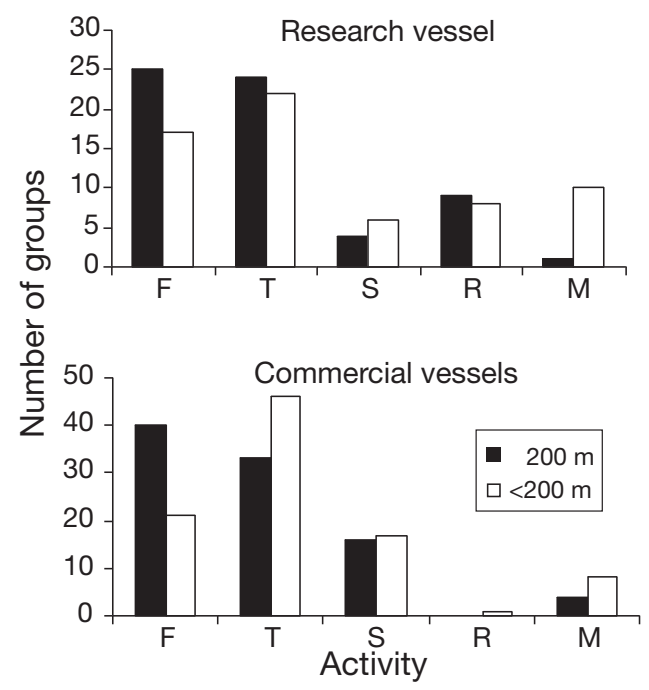

Fig. 2. Lagenorhynchus obscurus. Predominant activity at the moment commercial vessels (bottom panel) and the research vessel (top panel) were at $200 \mathrm{~m}$ and closer (50 and $100 \mathrm{~m}$ ) to a group of dolphins. F-feeding, T-traveling, $\mathrm{S}$ - socializing, $\mathrm{R}$ - resting, and $\mathrm{M}$ - milling ing and resting groups did not change or changed by a lesser proportion. When a group of traveling dolphins was approached by a commercial vessel, dolphins usually continued traveling. The commercial vessel, and thus the way of approaching dolphins, had an effect on the direction of change of activities (McNemar test $\chi^{2}=$ 19.33, $\mathrm{df}=10, \mathrm{p}=0.03$ ), while the the research vessel did not affect the likelihood of change from one activity to another and vice versa (McNemar test $\chi^{2}=15.6$, $\mathrm{df}=10, \mathrm{p}=0.11$ ).

\section{Effect of commercial vessels on activity pattern}

During the study period, 29 groups of dolphins were simultaneously followed by the research vessel and visited by commercial vessels. A total of 1093 intervals (each of 2 min) were recorded (a mean of 38 intervals per group), with 749 control and 344 impact intervals. Control and impact chains were constructed from 706
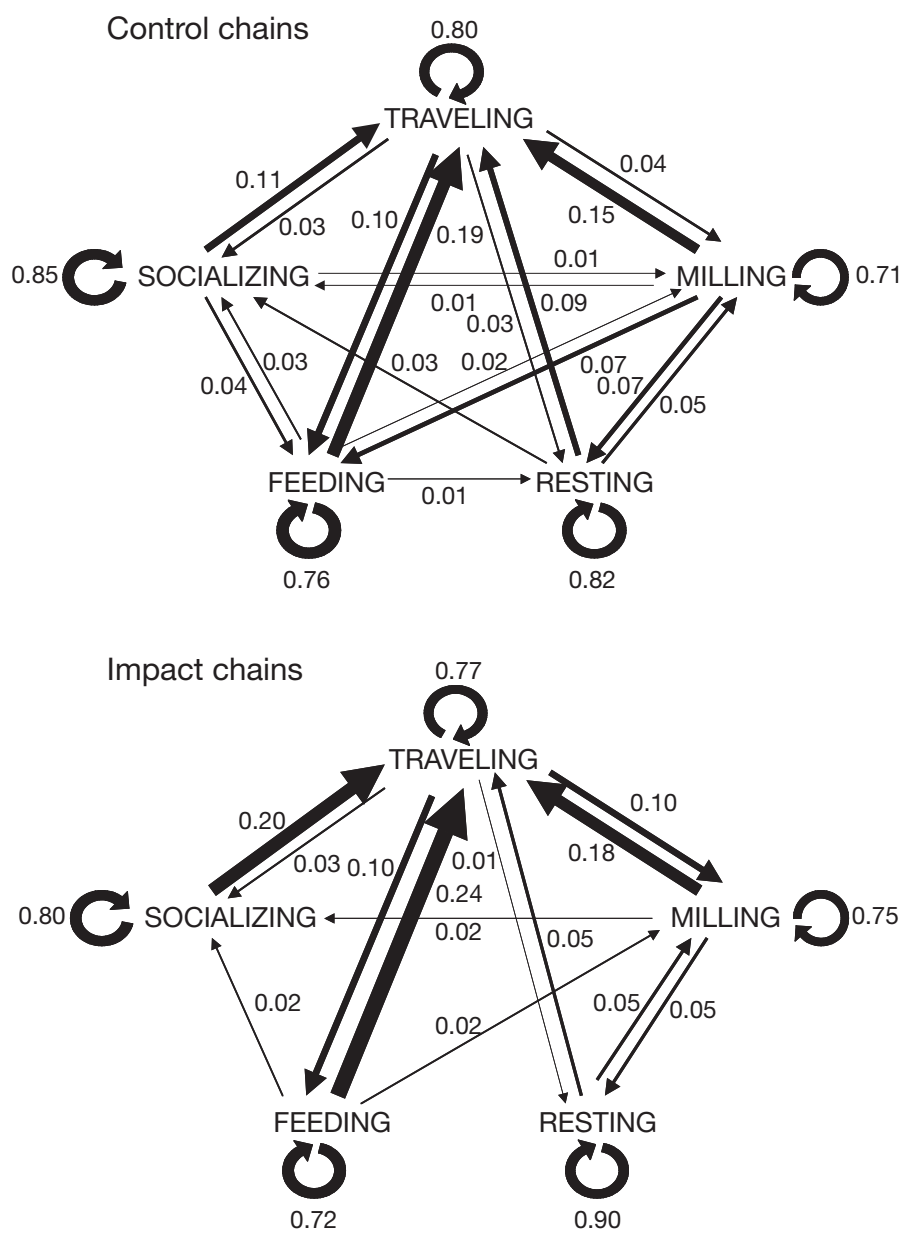

Fig. 3. Transition probabilities in control (upper) and impact (lower) chains. The behavioral states are defined in Table 1. Values are transition probabilities and arrow thickness represents these values 


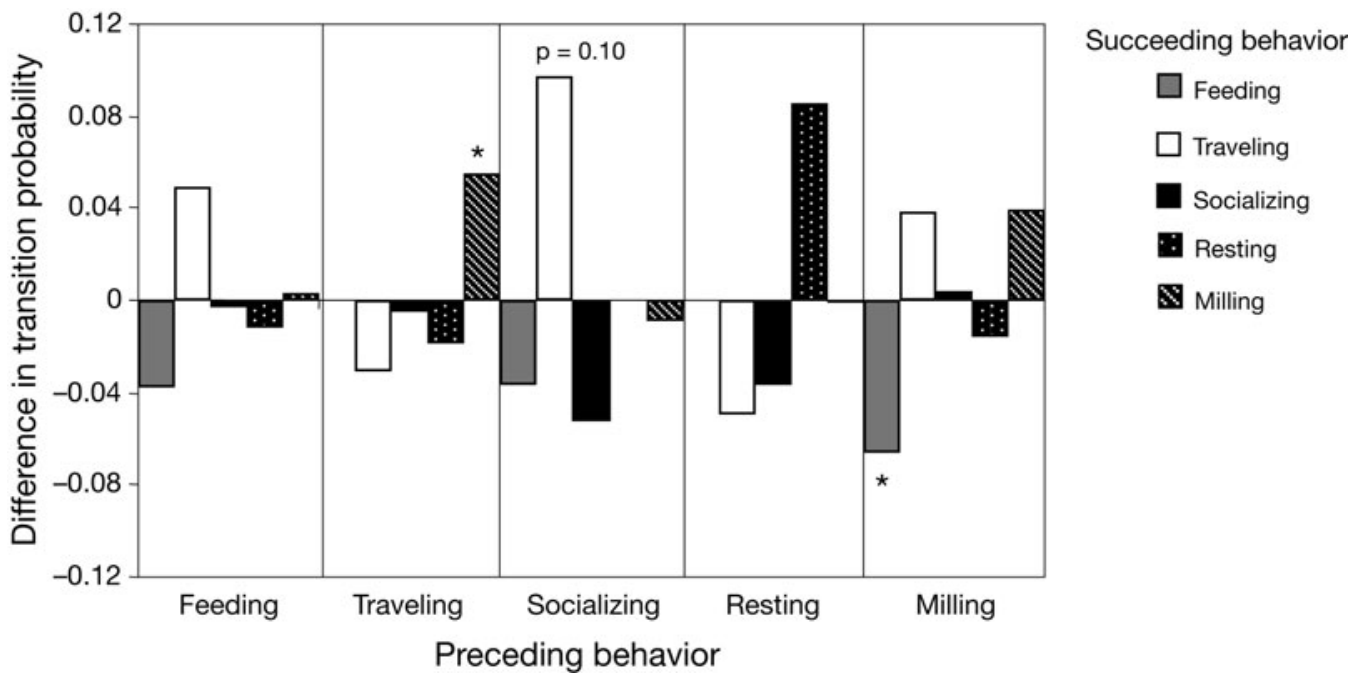

Fig. 4. Effect of commercial vessels on transition probabilities. Positive values indicate an increase in transition probability when commercial vessels are present and negative values indicate a decrease. Significant differences $(p<0.05)$ are denoted by an $(*)$

and 308 sequences, respectively. Transition probabilities are presented in Fig. 3. Whatever the preceding activity, the most probable succeeding activity was the same one (loops in Fig. 3). Traveling was usually the activity succeeding any other. However, traveling dolphins more frequently changed to feeding than to the other activities (Fig. 3).

Two transitions showed significant differences when commercial vessels were present: the transition $M \rightarrow F$ decreased and $\mathrm{T} \rightarrow \mathrm{M}$ increased (binomial test, $\mathrm{p}<0.05$, Fig. 4 ; see Table 1 for single letter abbreviations of behavioral states). This result indicates a shift in the strong relationship between feeding and traveling. Indeed, $\mathrm{F} \rightarrow \mathrm{T}$ increased from 0.19 to 0.24 while $\mathrm{T} \rightarrow \mathrm{F}$ remained equal $(0.10)$. In the presence of commercial vessels, the transition from all activities to feeding decreased. The transition $\mathrm{S} \rightarrow \mathrm{T}$ also showed an important although insignificant increase from 0.11 to 0.20 (binomial test, $\mathrm{p}=0.10$ ) ( Fig. 4).

The control transition probability matrix was stationary during the study period $\left(\Delta G^{2}=G_{\text {all 2-way }}^{2}\right.$

Table 2. Lagenorhynchus obscurus. Time budget and recurrence time (time to return to an activity once it was interrupted) of various activities in control and impact situations

\begin{tabular}{|c|c|c|c|c|c|}
\hline \multirow[t]{2}{*}{ Activity } & \multicolumn{3}{|c|}{ Time budget $(\%)$} & \multicolumn{2}{|c|}{ Recurrence time (min) } \\
\hline & Control & Impact & $Z$-test & Control & Impact \\
\hline Feeding & 22 & 15 & $2.51 ; \mathrm{p}<0.05$ & 9.21 & 13.66 \\
\hline Traveling & 41 & 42 & $0.09 ; \mathrm{p}>0.05$ & 4.83 & 4.76 \\
\hline Socializing & 16 & 9 & $2.82 ; \mathrm{p}<0.01$ & 12.62 & 22.26 \\
\hline Resting & 11 & 14 & $1.19 ; \mathrm{p}>0.05$ & 18.19 & 14.43 \\
\hline Milling & 10 & 20 & $4.43 ; \mathrm{p}<0.001$ & 20.01 & 9.76 \\
\hline
\end{tabular}

$\left.G_{\text {saturated }}^{2}=16.426 ; \mathrm{df}=32, \mathrm{p}=0.99\right)$. The model predicts that dolphins invest 41 and $22 \%$ of their time traveling and feeding, respectively (Table 2). In the presence of commercial vessels, the time budget for feeding $(Z$-test, $\mathrm{p}<0.05)$ and socializing $(Z$-test, $\mathrm{p}<$ $0.01)$ decreased, while the time budget for milling increased significantly $(Z$-test, $\mathrm{p}<0.001)$.

The time to return to feeding and socializing was longer in impact chains, while return to resting and milling took less time (Table 2). Mean first passage time differed depending on the activity (Fig 5). The time elapsed until dolphins were observed feeding was longer in the presence of commercial boats. The same pattern was observed for socializing and resting activities. Milling behavior was reached from any other behavior in a shorter period of time in the presence of commercial boats. Also, dolphins moved from feeding and socializing to traveling in less time.

\section{DISCUSSION}

Several short-term effects of tourist vessels on dusky dolphin behavior were detected. First, dolphins became more vulnerable to potential effects when feeding, possibly because boat operators found them more easily. When they see a flock of birds at a distance, they go directly to this location even if they cannot see dolphins. Also, when a boat approached dolphins that had been feeding, dolphins changed their behavior more frequently than when they had been traveling. 


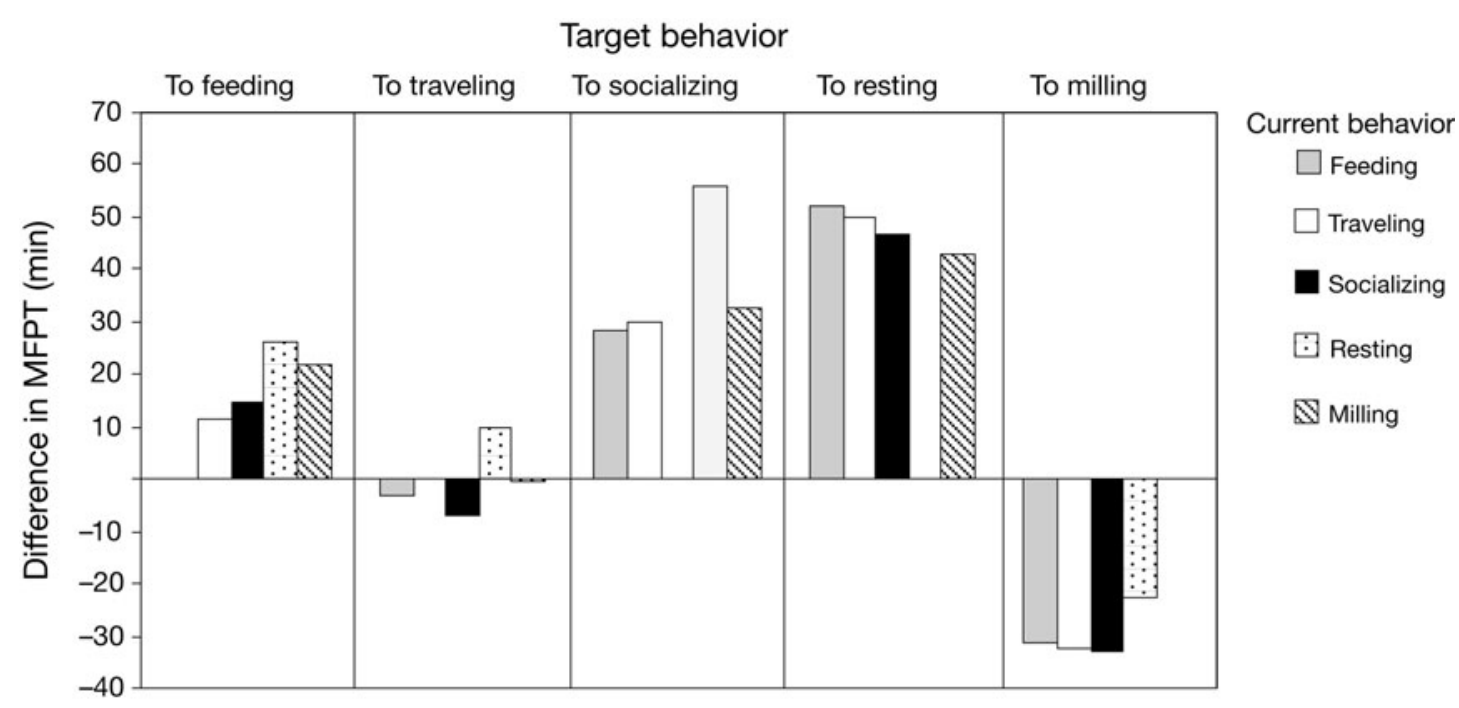

Fig. 5. Difference in mean first passage time (MFPT; min) between control and impact chains derived from properties of the transition matrix. MFPT is the time dolphins need to go from the current activity to a target activity

Over the longer term, the observed changes could produce significant effects, modifying the activity pattern, the time budget, and ultimately the population's energy intake-expenditure balance (Williams et al. 2006). Among the most important effects are the decrease in feeding and socializing time budgets. A reduction in social interactions may affect reproductive output. Moreover, a decrease in time spent feeding means a reduction in energy intake, and this effect may be more significant since dolphins would have to compensate for this reduction.

The results of the present study contrast with those found in Kaikoura, where effects from tourism were considered minimal despite the higher level of tourism activity in that location. Dusky dolphins in Kaikoura feed at night in a more individualistic way, when the deep scattering layer is shallow enough for dolphins to feed (never below 130 m) (Benoit-Bird et al. 2004). Dolphins there also occur in very large groups during daytime. They show daylight feeding on schooling fishes by herding the fish into a ball in a cooperative fashion, and in this case group sizes are smaller. This strategy was first well documented in Argentina (Würsig \& Würsig 1980) and also in other locations in New Zealand (Benoit-Bird et al. 2004). These alternative strategies are obviously related to differences in the environment and in prey availability. The effect of tour boats on the activity pattern of dolphins may therefore also differ in different locations. Feeding activity of dolphins in Kaikoura would remain undisturbed simply because it takes place at night, in contrast to that in Argentina.

The present study demonstrated that short-term changes in behavior, like the instantaneous response to vessel approach, must be complemented by longerterm assessment. During the first few minutes of the sighting, dolphins changed their behavior more frequently when they had been feeding than when they had been traveling. However, dolphins may have changed the activity, from feeding to traveling and vice versa, as their normal pattern. In the present work, we were able to evaluate not only this immediate response to the approach but also the chance of dolphins resuming the activity once the boat was present. In that sense, modeling behavior by first-order Markov chains allowed us to evaluate how the transition from one activity to another may or may not be modified over the longer term. As seen here, changes in transition probabilities lead to changes in activity budgets, time to return to an activity once it has been interrupted, and the time needed to go into an activity.

The analysis showed that when dolphins changed their activity to another, they usually changed to traveling, regardless of the preceding activity. However, when analyzing the effect of commercial vessels, most of the transitions from any activity to traveling increased, and transitions from any activity to feeding decreased. Additionally, commercial vessels found feeding groups more often, possibly due to the searching method used, since operators did not randomly search for dolphins but mainly looked for feeding bird flocks. This means that boats will differentially affect dolphin activity, since they are especially biased to feeding groups. Therefore, boats may mostly disrupt the transition $\mathrm{F} \rightarrow \mathrm{F}$ or $\mathrm{F} \rightarrow \mathrm{T}$ (see Table 1 for abbreviations), to which feeding time budget could be more sensitive, even if these transitions did not show statistically significant differences. 


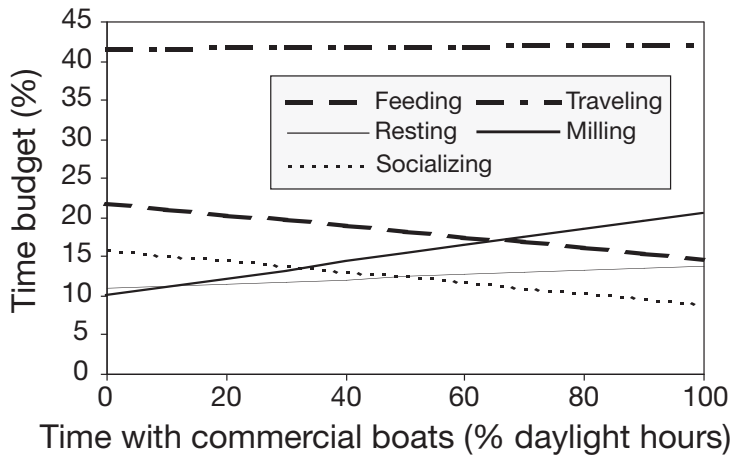

Fig. 6. Lagenorhynchus obscurus. Range of potential changes in time budget for various activities as a function of the proportion of time dolphins are subject to commercial vessels during daylight hours

Numerous studies on terrestrial mammals also showed changes in feeding activities under stress conditions. In most of these studies, human presence operated like feeding costs due to predation. Several carnivores as well as herbivores have been shown to reduce feeding time and thus food intake by increasing vigilance or alert behaviors (White et al. 1999, Duchesne et al. 2000, Taylor \& Knight 2003). In dusky dolphins, there is no evidence of such behaviors with respect to dolphin-watching boats, but the close proximity to feeding groups would likely interfere with feeding efficiency. The time needed to return to feeding once it was interrupted, as well as the waiting time for a feeding event to occur, increased in impact situations. All these changes may indicate more effort needed in searching for and handling food before dolphins can feed. Thus, foraging costs associated with searching and handling food may increase in the presence of commercial boats.

Very often, a feeding bout was followed by a traveling bout and vice versa, and this sequence may represent an important functional component of dusky dolphin activity pattern. Some traveling bouts possibly play a foraging function, like searching for food. This pattern may be associated with the spatial distribution of prey like Argentinian anchovies. As described for other pelagic prey species, Argentinian anchovies form compact shoals at depth during the day, but are widely scattered and closer to the surface at night (Hansen \& Madirolas 1996, Hansen et al. 2001, Gerlotto \& Paramo 2003). Thus, the degree of anchovy patchiness may determine the time dolphins invest in traveling and searching for food as well as the time elapsing between 2 feeding events. Degrati et al. (2008) found seasonal variation in time budgets while studying the activity pattern of dusky dolphins in the same area during a long period of time that included the whole autumn, following groups without commer- cial vessels in operation. They found that dolphins increased their traveling time but decreased their feeding time in autumn, and also suggested that this seasonal variation was related to a change in prey distribution and dolphin feeding strategy.

Impact assessment requires translation of changes in activity budget to energy balance since short-term responses can lead to long-term effects if the animals are unable to compensate for a reduced energy intake. Similar work in killer whales estimated the energetic cost of each activity, and translated the time budget to a $12 \mathrm{~h}$ energetic demand with and without boats (Williams et al. 2006). These authors found that even when time budgets were significantly different in the presence and absence of boats, the effect on the energetic demand was relatively small $(2.9 \%$ higher in the presence of boats), suggesting compensation by replacing one low-energy activity with another. In the present work, energetic cost of each activity was not considered; however, the disruption of the feeding pattern in terms of the decrease in feeding time budget, suggests a substantial decrease in energy gain.

Dusky dolphins in Argentinian shallow waters are described as diurnal feeders on pelagic fish (Würsig et al. 1997) like anchovies, although squids Illex argentinus, juvenile hake Merluccius hubbsi and other pelagic species may also be important items (KoenAlonso et al. 1998). The present study shows that dusky dolphins spend a relatively high proportion of their time feeding $(22 \%)$. Preliminary studies also suggested that dolphin abundance inside closed bays, like Golfo Nuevo, would increase during summer following an increase in prey availability during this season (Würsig \& Würsig 1980). Although prey abundance estimates and seasonal variation information are still lacking, preliminary acoustic surveys indicated the presence of anchovy schools throughout the year (M. Degrati pers. comm.). However, the spatial arrangement, depth distribution and school sizes may vary seasonally, thereby affecting foraging costs.

Tourist activity and tour boats overlap in space and time with dolphin feeding activity. Although it seems that groups of dolphins inhabiting Golfo Nuevo are not food-limited, boats could increase foraging costs and prevent dolphins from exploiting the resources within a portion of the habitat. Therefore, interference intensity may be high even when the level of the real resource is not limiting (Begon et al. 2006).

Several recommendations for management arise from the present work. The combination of the observed changes in behavior when commercial boats are present and a sensitivity analysis may enable determination of the level of perturbation dolphins are capable of resisting. Assuming control and impact 
activity budgets to be extremes in a continuum of potential impact level, the range of potential changes in activity budgets can be drawn, taking into account the proportion of time dolphins are disturbed. Commercial vessels were present in 344 of 749 intervals ( 2 min each). If we consider this ratio as an indirect measure of the time dolphins are with boats, it represents $\sim 45 \%$ of the daylight hours (Fig. 6), which would reduce the feeding time budget from 22 to $19 \%$, at least during months when tour boats operated. It was also found that dolphins invested $<11 \%$ of their time feeding during autumn (Degrati et al. 2008), possibly representing a minimum threshold value. This seasonal variation should be taken into account if an extension of the dolphin-watching season is planned, since extension of the presence of boats into autumn could significantly reduce the overall feeding and socializing time budget.

Moreover, several variables may be used in formulating guidelines for boat operators to reduce effects, like distance from dolphins and boat behavior during encounters. Boat behavior and distance are key in minimizing effects on the transitions $\mathrm{T} \rightarrow \mathrm{F}$ and $\mathrm{F} \rightarrow \mathrm{F}$ (see Table 1 for abbreviations), and thus on the feeding time budget.

Within a conservative perspective, our results suggest potential long-term effects, and the possibility of greater impacts if dolphin watching grows. Golfo Nuevo is a relatively small area within the distribution range of dusky dolphins in the southwest South Atlantic. If we consider that dolphins use Golfo Nuevo as a patch, they would need to sustain an energy intake rate greater than or equal to a minimum in order to balance their energy budget, before leaving the patch (van Gils et al. 2004). However, further research is needed to determine the allowable change in the normal activity budget before Golfo Nuevo can be classified as a suboptimal patch. Dusky dolphins are also affected by incidental mortality from fisheries along the Argentinian coast. In particular, annual mortality from trawl nets was estimated to be very close to threshold levels (Dans et al. 2003). This threat may be exacerbated by the pending development of a midwater trawl fishery for anchovies, which may lead to a potential conflict between tourism and fishing, and necessitate an integrated approach to conservation and management.

Acknowledgements. We thank Centro Nacional Patagónico (National Research Council of Argentina), Agencia Nacional de Promoción Científica y Tecnológica (PICT No. 4030/1999 and PICT No. 11679/2004), the University of Patagonia, Fundación Patagonia Natural, Fundación Vida Silvestre Argentina and BBVA Foundation (BIOCON 04), for the institutional, logistical and financial support given throughout this study. We also thank officers of the Tourism Government
Agency of Chubut; J. Owen, N. Ortiz and M. A. Díaz, for their assistance; the dolphin-watching operators and commercial boat skippers; and R. Benegas, S. Fernández, F. Alonso and D. Vissintini, who helped during the experiments. M. Coscarella provided helpful comments.

\section{LITERATURE CITED}

Altmann J (1974) Observational study of behavior: sampling methods. Behaviour 49:227-266

Bakeman R, Gottman JM (1997) Observing interaction. An introduction to sequential analysis, 2nd edn. Cambridge University Press, Cambridge

Barr K, Slooten E (1999) Effects of tourism on dusky dolphins at Kaikoura. Conservation Advisory Science Notes: 229. Department of Conservation, Wellington

Begon M, Townsend CR, Harper JL (2006) Ecology. From individuals to ecosystems, 4th edn. Blackwell Publishing, Oxford

Bejder L, Samuels A, Whitehead H, Gales N (2006) Interpreting short-term behavioural responses to disturbance within a longitudinal perspective. Anim Behav 72:1149-1158

Benoit-Bird KJ, Würsig B, McFadden CJ (2004) Dusky dolphin (Lagenorhynchus obscurus) foraging in two different habitats: active acoustic detection of dolphins and their prey. Mar Mamm Sci 20:215-231

Borkowski JJ, White PJ, Garrot RA, Davis T, Hardy AR, Reinhart DJ (2006) Behavioral responses of bison and elk in Yellowstone to snowmobiles and snow coaches. Ecol Appl 16:1911-1925

Caswell H (2001) Matrix population models. 2nd edn. Sinauer Associates, Boston, MA

Cipriano FW (1992) Behavior and occurrence patterns, feeding ecology and life history of dusky dolphins (Lagenorhynchus obscurus) off Kaikoura, New Zealand. PhD thesis, University of Arizona

> Constantine R, Brunton DH, Dennis T (2004) Dolphin-watching tour boats change bottlenose dolphin (Tursiops truncatus) behaviour. Biol Conserv 117:299-307

Coscarella MA, Dans SL, Crespo EA, Pedraza SN (2003) Potential impact of unregulated dolphin watching activities in Patagonia. J Cetacean Res Manag 5:77-84

Crespo AE, Pedraza SN, Coscarella M, García NA and others (1997) Distribution of dusky dolphins Lagenorhynchus obscurus (Gray, 1828) in the southwestern Atlantic Ocean with notes on the size of herds. Rep Int Whaling Comm 47: 693-698

Dans SL, Crespo EA, Koen Alonso M, Pedraza SN (2003) Incidental catch of dolphins in trawling fisheries off Patagonia, Argentina: Can populations persist? Ecol Appl 13:754-762

Degrati M, Dans SL, Crespo EA, Pedraza SN, Garaffo GV (2008) Diurnal behavior of dusky dolphins Lagenorhynchus obscurus in Golfo Nuevo, Argentina. J Mammal 89:50-56

> Duchesne M, Cote SD, Barret C (2000) Responses of woodland caribou to winter ecotourism in the Charlevoix Biosphere Reserve, Canada. Biol Conserv 96:311-317

Garaffo GV, Dans SL, Pedraza SN, Crespo EA, Degrati M (2007) Habitat use by dusky dolphin in Patagonia: How predictable is their location? Mar Biol 152:165-177

Gerlotto F, Paramo J (2003) The three-dimensional morphology and internal structure of clupeid schools as observed using vertical scanning multibeam sonar. Aquat Living Resour 16:113-122 
Gill JA, Norris K, Sutherland WJ (2001) The effects of disturbance on habitat use by black-tailed godwits Limosa limosa. J Appl Ecol 38:846-856

Grinstead CM, Snell JL (1997) Introduction to probability, 2nd edn (revised). American Mathematical Society, Providence, RI

Hansen JE, Madirolas A (1996) Distribución, evaluación acústica y estructura poblacional de la anchoita (Engraulis anchoita). Resultados de las campanas de 1993. Rev Investig Desarro Pesq 110:5-21

Hansen JE, Martos P, Madirolas A (2001) Relationship between spatial distribution of the Patagonian stock of Argentine anchovy, Engraulis anchoita, and sea temperatures during late spring to early summer. Fish Oceanogr 10:193-206

Hill MF, Witman JD, Caswell H (2004) Markov chain analysis of succession in a rocky subtidal community. Am Nat 164: E46-E61

Hoyt E (2001) Whale-watching 2001: worldwide tourism numbers, expenditures and expanding socioeconomic benefits. International Fund for Animal Welfare, Yarmouth Port, MA

Koen-Alonso M, Crespo EA, Garcia NA, Pedraza SN, Coscarella MA (1998) Diet of dusky dolphins (Lagenorhynchus obscurus), in waters off Patagonia, Argentina. Fish Bull 96:366-374

Lehner PN (1998) Handbook of ethological methods, 2nd edn. Cambridge University Press, Cambridge

Lusseau D (2003) Effects of tour boats on the behavior of bottlenose dolphins: using Markov chains to model anthropogenic impacts. Conserv Biol 17:1785-1793

Lusseau D (2005) Residency pattern of bottlenose dolphins Tursiops spp. in Mildford Sound, New Zealand, is related to boat traffic. Mar Ecol Prog Ser 295:265-272

Mann J, Connor RC, Barre LM, Heithaus MR (2000) Female reproductive success in bottlenose dolphins (Tursiops $\mathrm{sp}$. ): life history, habitat, provisioning, and group-size effects. Behav Ecol 11:210-219

Markowitz TM (2004) Social organization of the New Zealand dusky dolphin. PhD Thesis, Texas A\&M University

Editorial responsibility: Lissandro Benedetti-Cecchi, Pisa, Italy
Mouzo FH, Garza ML, Izquierdo JF, Zibecchi RO (1978) Rasgos de la geología submarina del Golfo Nuevo (Chubut). Acta Oceanogr Argent 2:69-91

Nowacek SM, Wells RS, Solow AR (2001) Short-term effects of boat traffic on bottlenose dolphins, Tursiops truncatus, in Sarasota Bay, Florida. Mar Mamm Sci 17:673-688

Stockin KA, Lusseau D, Binedell V, Wiseman N, Orams MB (2008) Tourism affects the behavioural budget of the common dolphin Delphinus sp. in the Hauraki Gulf, New Zealand. Mar Ecol Prog Ser 355:287-295

Taylor AR, Knight RL (2003) Wildlife responses to recreation and associated visitor perceptions. Ecol Appl 13:951-963

> van Gils JA, Edelaar P, Escudero G, Piersma T (2004) Carrying capacity models should not use fixed prey density thresholds: a plea for using more tools of behavioural ecology. Oikos 104:197-204

White D, Kendall KC, Picton HD (1999) Potential energetic effects of mountain climbers on foraging grizzly bears. Wildl Soc Bull 27:146-151

Williams R, Trites AW, Bain DE (2002) Behavioural responses of killer whales (Orcinus orca) to whale-watching boats: opportunistic observations and experimental approaches. J Zool (Lond) 256:255-270

Williams R, Lusseau D, Hammond P (2006) Estimating relative energetic costs of human disturbance to killer whales (Orcinus orca). Biol Conserv 133:301-311

Würsig B, Bastida R (1986) Long-range movement and individual associations of two dusky dolphins (Lagenorhynchus obscurus) off Argentina. J Mammal 67: 773-774

Würsig B, Würsig M (1980) Behavior and ecology of dusky dolphins Lagenorhynchus obscurus in the South Atlantic. Fish Bull 77:871-890

Würsig B, Cipriano F, Slooten E, Constantine R, Barr K, Yin S (1997) Dusky dolphins (Lagenorhynchus obscurus) off New Zealand: status of present knowledge. Rep Int Whal Comm 47:715-722

Zar JH (1996) Biostatistical analysis, 3rd edn. Prentice Hall, Upper Saddle River, NJ

Submitted: March 25, 2008; Accepted: June 30, 2008 Proofs received from author(s): September 29, 2008 